\title{
Population structure and inherited genetic disorders in the Bedouin of the Negev
}

\author{
AH Bittles ${ }^{1,2}$ (D) \\ Received: 10 July 2019 / Accepted: 14 July 2019 / Published online: 25 July 2019 \\ (C) Springer-Verlag GmbH Germany, part of Springer Nature 2019
}

In their paper on genetic disease among the Bedouin Arab population in the Negev region of southern Israel, Singer et al. attribute the high infant mortality rate of 11 per 1000 and the inheritance of numerous genetic diseases to consanguineous marriage. While not disagreeing with this conclusion in general terms, before calling for a raised awareness of the adverse sequelae of consanguinity and specific interventions to limit consanguinity via programmes incorporating targeted genetic screening, it is appropriate to consider the possible roles of other major contributory population variables in the disease profile of this community.

The traditionally nomadic Bedouin are believed to have moved from the Arabian Peninsula to southern Israel and the Sinai around $700 \mathrm{AD}$, and they presently account for approximately $4 \%$ of the population of Israel (Shalev et al. 2017). Bedouin social structure is highly hierarchical, comprising extended nuclear families, tribes, and clans, with strict tribal endogamy and intra-familial consanguinity strongly favoured (Markus et al. 2014). In a study on Bedouin couples conducted during 2009-2010, the prevalence of consanguineous marriage was estimated to be $44.8 \%$, equivalent to a mean coefficient of inbreeding $(\alpha)$ of 0.0238 , with first-cousin unions between a man and his father's brother's wife (FBD) preferred (Na'amnih et al. 2014). Through time, tribes may aggregate or disaggregate in response to changing political and environmental circumstances (Nabulsi 1995), but marriages between couples who belong to different clans are generally forbidden (Markus et al. 2014).

As detailed by Singer et al., the numbers and population structure of the Negev Bedouin have changed very

AH Bittles

a.bittles@ecu.edu.au; abittles@ccg.murdoch.edu.au

1 School of Medical and Health Sciences, Edith Cowan University, Perth, WA 6027, Australia

2 Centre for Comparative Genomics, Murdoch University, Perth, WA 6051, Australia significantly since the creation of the State of Israel in 1948, with nomadism restricted to specified areas within the presentday international boundaries. Following the expulsion of many Bedouin to neighbouring countries, their numbers in the Negev declined from an estimated pre-1948 population of 65,000 to 90,000 to $\sim 11,000$. According to Singer et al., the subsequent high fertility of the Negev Bedouin community has resulted in a present-day total of $\sim 240,000$ persons, subdivided into more than 100 tribal units which vary in size from 100 to 10,000 individuals (Markus et al. 2014).

Population changes of this nature strongly suggest that genetic drift would have been exacerbated during the course of the last three generations. But given the lack of information on the family and tribal structure of the Bedouin who were expelled post-1948, the comparative roles of drift, familial and tribal endogamy, and preferential consanguinity on the transmission of disease genes are a matter of conjecture. Comprehensive information on the profile of single-gene disorders within the Bedouin community is available via the Israeli National Genetic Database of Mendelian disorders, initiated in 2006 by Prof. Joel Zlotogora and his colleagues (Zlotogora et al. 2007; Zlotogora and Patrinos 2017).

In Israel, prereproductive genetic screening can be offered for a range of inherited diseases, including severe rare disorders that are locality-specific or restricted to the members of extended families (hamulah) (Shalev et al. 2017), and thus indicative of quite recent founder mutations (Zlotogora et al. 2016). However, a number of issues and reservations arise in planning and applying genetic screening to the Negev Bedouin. Singer et al. indicate that while $\sim 60 \%$ of the overall Bedouin population have accepted sedentarization and live in townships with access to comprehensive educational and health facilities, $\sim 40 \%$ of their co-citizens live in villages with high rates of poverty and unemployment, and no access to basic facilities such as running water, electricity, and health care. Practical concerns arise; for example, will it be possible to efficiently organize the requisite sample collection procedures and provide appropriate genetic counselling, clinical 
care, and treatment to the inhabitants of these villages? However, there also is a moral dilemma as to whether efforts should not primarily be concentrated on the provision of basic health care measures and facilities which at least should serve to significantly reduce the existing high infant mortality rate.

Given the traditionally favoured role of close-kin marriages in Bedouin communities, it is important that the potential adverse impact of consanguinity on health is not over-stated (Bittles 2008). In Table 2 of their review, Singer et al. report extremely high carrier rates for a wide range of disorders, e.g. 1:5 for Carmi syndrome and maple syrup urine disease respectively, each with one OMIM number listed, and 1:6 for Bartter syndrome with four OMIM numbers cited. It is difficult to envisage how such high carrier rates can be ascribed to consanguineous marriage alone, especially in a population that so recently has experienced profound numerical and structural changes and is characterized by multiple endogamous subdivisions. The value of genealogical information in addressing such questions has been clearly demonstrated in investigations conducted on other Arab communities in Israel (Zlotogora et al. 2006). A similar approach could appropriately be incorporated into the genetic screening programme envisaged for the Bedouin.

\section{References}

Bittles AH (2008) A community genetics perspective on consanguineous marriage. Public Health Genomics 11:324-330

Markus B, Alshafee I, Bork OS (2014) Deciphering the fine structure of tribal admixture in the Bedouin population using genomic data. Heredity 112:182-189

Na'amnih W, Romano-Zelekha O, Kabaha A, Rubin LP, Bilenko N, Jaber L, Honovich M, Shohat T (2014) Prevalence of consanguineous marriages and associated factors among Israeli Bedouins. J Commun Genet 5:395-398

Nabulsi A (1995) Mating patterns in the Abbad tribe in Jordan. Soc Biol 42:162-174

Shalev SA, Zlotogora J, Shalata A, Levy-Lahad E (2017) Medical genetics in Israel's diverse population. Lancet 389:2453-2455

Zlotogora J, Patrinos GP (2017) The Israel National Genetic database: a 10-year experience. Hum Genomics 11:5

Zlotogora J, Hujerat Y, Barges S, Shalev SA, Chakravarti A (2006) The fate of 12 recessive mutations in a single village. Ann Hum Genet 71:202-208

Zlotogora J, van Baal S, Patrinos GP (2007) Documentation of inherited disorders and mutation frequencies in the different religious communities in Israel in the Israeli National Genetic Database. Hum Mutat 28:944-949

Zlotogora J, Grotto I, Kaliner E, Gamzu R (2016) The Israeli national population program of genetic carrier screening for reproductive purposes. Genet Med 18:203-206

Publisher's note Springer Nature remains neutral with regard to jurisdictional claims in published maps and institutional affiliations. 